\title{
Comparison of lumbar multifidus thickness and perceived exertion during graded superman exercises with or without an abdominal drawing-in maneuver in young adults
}

\author{
Young-In Hwang' ${ }^{1}$, Du-Jin Park ${ }^{2, *}$ \\ 'Department of Physical Therapy, College of Biohealth, Hoseo University, Seosan, Korea \\ ${ }^{2}$ Department of Physical Therapy, College of Health Medicine, Kaya University, Gimhae, Korea
}

The present study aimed to investigate lumbar multifidus (LM) thickness and perceived exertion during graded superman exercises (GSE) or GSE with an abdominal drawing-in maneuver (GSE-AD) in young adults. Twelve young adult males and females, who were informed of the purpose and procedures of this study and then gave their voluntary consent to participate, were included in this study. All subjects randomly performed three GSE and GSE-AD over 3 days. Ultrasonography was used to measure the $L M$ thickness to the left and right of the $L 5$ region. Additionally, the issue of whole-body fatigue felt by the subject while performing the GSE or GSE-AD was measured using the Borg scale. The intrarater reliability of the LM measurement was found to be intraclass correlation coefficient $(\mathrm{ICC}[3,1])=0.97(0.87-0.99)$ at resting and
$\operatorname{ICC}(3,1)=0.94(0.78-0.99)$ at contraction. Both the left and right LM showed significantly higher contraction during the grade 3 GSE $(P<$ $0.05)$. The whole-body fatigue was significantly greater following GSE 2 and 3 than following GSE-AD 2 and $3(P<0.05)$. In particular, GSE-AD had a significantly lower Borg score compared to GSE $(P<0.05)$ and did not show any significant difference in muscle thickness $(P>0.05)$. It is recommended that the abdominal drawing-in maneuver be applied with grade 3 GSE to enhance stability and reduce spinal fatigue.

Keywords: Superman exercise, Lumbar multifidus, Ultrasonography, Abdominal drawing-in maneuver

\section{INTRODUCTION}

The lumbar multifidus (LM) is one of the primary stabilizing muscles of the lumbar spine. LM dysfunction is closely related to low back pain (LBP) (MacDonald et al., 2009). Recent studies have suggested that LM atrophy is more closely related to chronic back pain than to recurrent or acute back pain (Goubert et al., 2016). In particular, the LM exhibits activity impairment at L5 compared with the muscle at L2-4 due to frequent lumbar instability around the corresponding segment (Wallwork et al., 2009; Wilke et al., 1995).

Because natural recovery from LM atrophy and dysfunction is rare, these conditions, combined with other factors, are likely to cause recurrence of LBP (Hides et al., 1996). Therefore, LM training is an important part of clinical therapy (Freeman et al., 2010). Various exercises, including the abdominal drawing-in maneuver (ADIM), bird dog, bridge, and superman are recommended for increasing LM activity; these lumbar stabilization exercises are effective not only in reducing the recurrence of LBP but also in restoring the function of the LM (Hides et al., 2001; Kim et al., 2016).

Few studies have succeeded in demonstrating the effect of graded superman exercises (GSE) for the treatment of LM dysfunction, and those that have analyzed the effect employed surface electromyography (EMG) to measure LM activity (Ekstrom et al., 2008; Kim et al., 2016). Measurement of LM by surface EMG is limit-
${ }^{*}$ Corresponding author: Du-Jin Park (D) https://orcid.org/0000-0002-5658-3343 Department of Physical Therapy, College of Health Medicine, Kaya University, 208 Samgye-ro, Gimhae 50830, Korea

Tel: +82-55-330-1047, Fax: +82-55-344-5285, E-mail: djpark35@kaya.ac.kr Received: June 11, 2018 / Accepted: July 16, 2018
This is an Open Access article distributed under the terms of the Creative Commons Attribution Non-Commercial License (http://creativecommons.org/licenses/by-nc/4.0/) which permits unrestricted non-commercial use, distribution, and reproduction in any medium, provided the original work is properly cited. 
ed, and ultrasound imaging is recommended as an evaluation tool instead, as it is suitable for static and dynamic morphometric research (Wong et al., 2013).

Additionally, information related to the level of performance difficulty is needed because GSE contains many dynamic elements. In particular, stability of the spine is essential when raising the arms and legs together. As lordotic curvature of the lumbar spine increases, LM activity may increase, but excessive lordotic curvature can be painful. Aggravation of pain may cause altered motor control in people with LBP (van Dieën et al., 2003). Previous studies have found that combining an ADIM with the exercise in the prone position had positive effects such as reducing lordotic curvature and increasing muscle activity (Kim et al., 2014; Park et al., 2011). Therefore, the present study aimed to investigate LM thickness and perceived exertion during GSE with or without an ADIM in young adults.

\section{MATERIALS AND METHODS}

\section{Subjects}

Twelve young adult males and females, who were informed of the purpose and procedures of this study and then gave their voluntary consent to participate, were included in this study. The selection criteria for this study were as follows: those who have not experienced LBP within the past six months, those who were able to perform the exercise for this study, those with a body mass in$\operatorname{dex}$ (BMI) of $>30 \mathrm{~kg} / \mathrm{m}^{2}$, and those who had no other physical defects. The procedures of this study were approved by the Research Ethics Committee of the Kaya University (approval number: 20180217).

\section{Ultrasonography}

For the ultrasonography, a 2.5-6 MHz curved probe (Prosound 2, Hitachi Aloka Medical, Tokyo, Japan) was used to measure the LM thickness to the left and right of the L5 region. The subject assumed a prone position on the table and was supported by a pil- low under the belly to keep the lumbar spine flat. The LM thickness was measured in a resting state while the lumbosacral junction angle was kept at $10^{\circ}$ or lower (Larivière et al., 2018).

\section{Graded superman exercises}

Before the experiment started, a 20-min education session on the exercise was provided, followed by a 10-min rest. The GSE grades were performed as follows (Fig. 1). For GSE 1, the arms were spread at $150^{\circ}$ in the starting position, raised as high as possible from the ground, and then lowered. For GSE 2, the legs were spread at $30^{\circ}$ in the starting position, raised as high as possible from the ground, and then lowered. For GSE 3, both arms and both legs were raised at the same time in the same matter as described above.

\section{Abdominal drawing-in maneuver}

All the subjects learned the ADIM using a pressure biofeedback unit (PBU TN37343; Chattanooga Group, Inc., Hixson, TN, USA). First, subjects were instructed to take a prone position with their arms by their sides and head in the midline. Then, the PBU was placed under the abdomen centered on the navel and with the distal edges of the pad in line with the right and left anterior superior iliac spines. Next, the bulb was inflated to a pressure of 70 $\mathrm{mmHg}$, and subjects were instructed to reduce the pressure to $4-10 \mathrm{mmHg}$ by drawing in the abdomen without spinal or pelvic movements and without bulging of the abdomen (Kahlaee et al., 2017).

\section{Procedures}

The subjects then performed the GSE or GSE with ADIM (GSE-AD). Variations on the GSE and GSE-AD were performed in random order, with only one exercise performed per day to rule out the effects of the previous exercise. The exercises were conducted over 3 days. A 5-min rest was given after each exercise, and the mean value of three measurements was used for the analysis.

To normalize the change in LM thickness, the following equa-
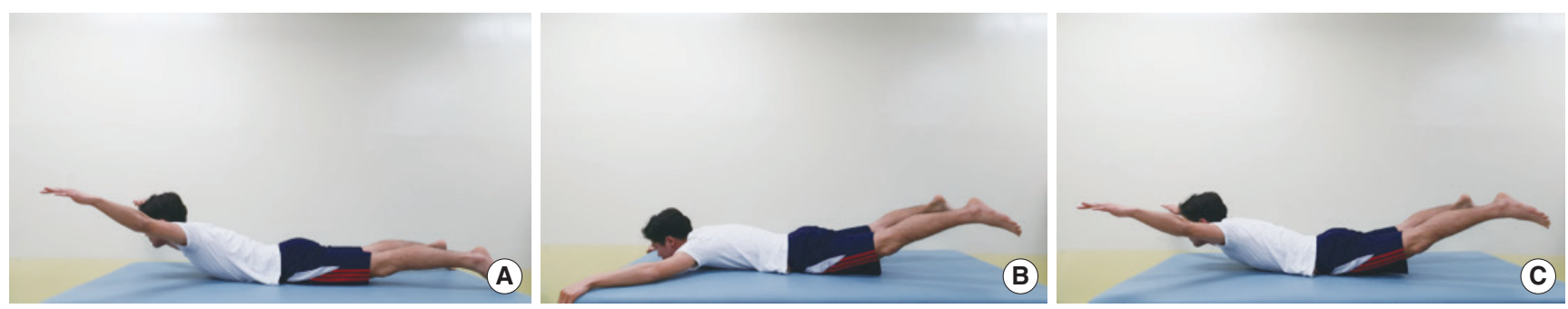

Fig. 1. Graded superman exercises (GSE): (A) GSE 1: subjects lifted both arms, (B) GSE 2: subjects lifted both legs, (C) GSE 3: subjects lifted both arms and legs. 
tion was used (Kiesel et al., 2007): LM=(LM thickness at contraction $-\mathrm{LM}$ thickness at rest)/LM thickness at rest $\times 100$. Additionally, the issue of whole-body fatigue felt by the subject while performing the GSE or GSE-AD was measured using the Borg scale (Borg CR-10) (Borg, 1990).

\section{Statistical analysis}

The intra-rater reliability of the ultrasound measurement was determined by the intraclass correlation coefficient (ICC[3,1]). A Friedman test was used to analyze changes in LM thickness and results of the perceived exertion scale for the GSE. The Wilcoxon signed-rank test was used to analyze the differences among the GSE levels, and the Mann-Whitney test was used to compare the LM thickness and the Borg value between GSE and GSE-AD. The measurement data were analyzed using IBM SPSS ver. 18.0 (IBM Co., Armonk, NY, USA), and the significance level was set at $\alpha=0.05$.

\section{RESULTS}

The mean age, height, weight, and BMI of the subjects were $24.58 \pm 1.88$ years, $165.77 \pm 9.50 \mathrm{~cm}, 62.07 \pm 13.46 \mathrm{~kg}$, and $22.35 \pm 2.92 \mathrm{~kg} / \mathrm{m}^{2}$, respectively. The intrarater reliability for the LM measurement was $\operatorname{ICC}(3,1)=0.97(0.87-0.99)$ at rest and $\operatorname{ICC}(3,1)=0.94(0.78-0.99)$ with contraction. The left and right LM contractions during the GSE showed significant differences (Table 1). Both the left and right LM showed significantly higher contraction during the grade 3 GSE. The whole-body fatigue was significantly greater following GSE 2 and 3 than following GSE-

Table 1. Comparison of lumbar multifidus thickness and perceived exertion during graded superman exercises with or without an abdominal drawing-in maneuver $(n=12)$

\begin{tabular}{lrrr}
\hline Variable & Grade 1 & Grade 2 & \multicolumn{1}{c}{ Grade 3 } \\
\hline GSE & & & \\
Left LM $(\%)^{*}$ & $11.67 \pm 5.92^{\mathrm{a}}$ & $16.19 \pm 4.27^{\mathrm{b}}$ & $34.29 \pm 3.83^{\mathrm{c}}$ \\
Right LM $(\%)^{*}$ & $13.28 \pm 5.66^{\mathrm{a}}$ & $18.97 \pm 7.19^{\mathrm{b}}$ & $34.79 \pm 5.30^{\mathrm{c}}$ \\
Borg scores* & $2.00 \pm 1.04^{\mathrm{a}}$ & $3.17 \pm 1.34^{\mathrm{b}}$ & $4.67 \pm 1.56^{\mathrm{c}}$ \\
GSECA & & & \\
Left LM $(\%)^{*}$ & $11.64 \pm 5.58^{\mathrm{a}}$ & $16.17 \pm 6.42^{\mathrm{b}}$ & $33.46 \pm 5.14^{\mathrm{c}}$ \\
Right LM $(\%)^{*}$ & $12.85 \pm 6.30^{\mathrm{a}}$ & $18.51 \pm 8.51^{\mathrm{b}}$ & $34.30 \pm 4.25^{\mathrm{c}}$ \\
Borg scores $^{*}$ & $1.58 \pm 0.67^{\mathrm{a}}$ & $2.00 \pm 0.74^{\mathrm{a}}$ & $3.33 \pm 1.23^{\mathrm{b}}$ \\
\hline
\end{tabular}

Values are presented as mean \pm standard deviation.

GSE, graded superman exercises, GSE-AD, graded superman exercises with an abdominal drawing-in maneuver, LM, lumbar multifidus,

The values with different superscripts $(a, b, c)$ in the same column are significantly different $(P<0.05) .{ }^{*} P<0.05$, statistically significant.
AD 2 and 3 (Table 2).

\section{DISCUSSION}

LM atrophy and abnormalities in the ability to control movement, such as altered patterns of LM recruitment, are observed in patients with LBP (Danneels et al., 2002; MacDonald et al., 2009). In a previous study, patients with LBP were pain free after 4 weeks of medical treatment or motor control exercise treatment, but normal LM symmetry was recovered only in patients who received motor control exercise treatment for 4-10 weeks (Hides et al., 1996). In clinical practice, various lumbar stabilization exercises have been applied to treat LM dysfunction. Most electromyographic studies have reported that the superman exercise is effective in activating LM (Ekstrom et al., 2008; Oliver et al., 2010). However, few ultrasonographic studies have investigated the effects of GSE on the LM, and few have identified the effect of GSECA for increasing the stability of the spine. It was to investigate these factors that the present study was conducted.

In this study, grade 3 GSE resulted in significantly higher left and right LM contraction than did grades 1 and 2 . This supports the results of previous research showing that the activity of the LM was highest in the posture of lifting both arms and legs while performing GSE (Kim et al., 2016). However, direct comparison is limited because the previous research did not include GSE grades 1 and 2 , i.e., GSE using only arms or only legs. In the present study, grade 3 was performed following the recommendation

Table 2. Comparison of lumbar multifidus thickness and perceived exertion between two interventions

\begin{tabular}{lrrrr}
\hline Variable & GSE & GSE-AD & $Z$ & $P$ \\
\hline Grade 1 & & & & \\
Left LM (\%) & $11.67 \pm 5.92$ & $11.64 \pm 5.58$ & -0.23 & 0.84 \\
Right LM $(\%)$ & $13.28 \pm 5.66$ & $12.85 \pm 6.30$ & -0.35 & 0.73 \\
Borg scores & $2.00 \pm 1.04$ & $1.58 \pm 0.67$ & -0.93 & 0.41 \\
Grade 2 & & & & \\
Left LM (\%) & $16.19 \pm 4.27$ & $16.17 \pm 6.42$ & -0.23 & 0.84 \\
Right LM $(\%)$ & $18.97 \pm 7.19$ & $18.51 \pm 8.51$ & -0.06 & 0.98 \\
Borg scores* & $3.17 \pm 1.34$ & $2.00 \pm 0.74$ & -2.30 & 0.03 \\
Grade 3 & & & & \\
Left LM (\%) & $34.29 \pm 3.83$ & $33.46 \pm 5.14$ & -0.81 & 0.93 \\
Right LM $(\%)$ & $34.79 \pm 5.30$ & $34.30 \pm 4.25$ & -0.12 & 0.44 \\
Borg scores* & $4.67 \pm 1.56$ & $3.33 \pm 1.23$ & -2.23 & 0.03 \\
\hline
\end{tabular}

Values are presented as mean \pm standard deviation.

GSE, graded superman exercises, GSE-AD, graded superman exercises with an abdominal drawing-in maneuver, LM, lumbar multifidus.

${ }^{*} P<0.05$, statistically significant. 
that exercising using both arms and legs could increase the demand on the trunk muscles. Based on the results of the present study, grade 1 is recommended as the first step for recovery of LM function following acute dysfunction, as its performance difficulty and LM contraction were lowest compared with the other grades. Then, it is recommended to proceed to grade 2 , followed by grade 3. This positional change is effective in eliciting better treatment compliance when sustained motivation and positive perception of exercise are required for both the therapist and the client (Ben Salah Frih et al., 2009).

In previous EMG studies, the superman exercise (GSE 3) lifting both arms and legs showed the highest peak amplitude of LM activity compared with other back extension exercises (Kim et al., 2016), with an activity as high as $61 \%-77 \%$ of the maximum voluntary contraction (\% MVIC) of LM (Ekstrom et al., 2008; Oliver et al., 2010). In the present study, the left and right LM thickness in grade 3 was $18.1 \%-22.62 \%$ and $15.82 \%-21.51 \%$ higher than those of grades 1 and grade 2, respectively, and the change in the left and right LM thickness was very large (over $33 \%)$. It is difficult to directly compare the results of the EMG studies with the results of the present study, but considering that the change in muscle thickness is an indicator of muscle activity (Djordjevic et al., 2015), it can be concluded that grade 3 can be specifically used for inducing changes in LM thickness and activity. Furthermore, these results suggest that the use of both arms and legs at the same time enhanced the movement, eliciting the maximal LM activity. This seems to have contributed to the elevated difficulty of performance. In this way, grade 3 causes high LM muscle contraction and a high level of performance difficulty. However, GSE-AD had a significantly lower Borg score compared to GSE and did not show any significant difference in muscle thickness. This is because the application of ADIM reduced the lordotic curvature, resulting in reduced fatigue levels.

It is recommended that the GSE be performed as motor control training of the LM or core muscle training and conditioning in athletes after initial rehabilitation, when pain is well controlled, rather than during initial rehabilitation in patients with LBP. In particular, care should be taken with LBP patients' safety during grade 3. It is recommended that the ADIM be applied with grade 3 GSE to enhance stability and reduce spinal fatigue. Further research on the effects of GSE and GSE-AD in patients with LBP is needed in the future.

One limitation of this study is the absence of data on the activity or thickness of surrounding muscles such as the erector spinae and gluteal muscles, which made impossible to assess compensa- tory activity in the surrounding muscles during the GSE performance. Therefore, future study is needed to examine the correlation between LM activity and compensatory activity of surrounding muscles during GSE.

\section{CONFLICT OF INTEREST}

No potential conflict of interest relevant to this article was reported.

\section{ACKNOWLEDGMENTS}

This research was supported by the National Research Foundation of Korea (NRF) grant funded by Ministry of Science and ICT (No. 2017R1C1B5074795).

\section{REFERENCES}

Ben Salah Frih Z, Fendri Y, Jellad A, Boudoukhane S, Rejeb N. Efficacy and treatment compliance of a home-based rehabilitation programme for chronic low back pain: a randomized, controlled study. Ann Phys Rehabil Med 2009;52:485-496.

Borg G. Psychophysical scaling with applications in physical work and the perception of exertion. Scand J Work Environ Health 1990;16 Suppl 1:55-58.

Danneels LA, Coorevits PL, Cools AM, Vanderstraeten GG, Cambier DC, Witvrouw EE, De CH. Differences in electromyographic activity in the multifidus muscle and the iliocostalis lumborum between healthy subjects and patients with sub-acute and chronic low back pain. Eur Spine J 2002;11:13-19.

Djordjevic O, Konstantinovic L, Miljkovic N, Bijelic G. Relationship between electromyographic signal amplitude and thickness change of the trunk muscles in patients with and without low back pain. Clin J Pain 2015;31:893-902.

Ekstrom RA, Osborn RW, Hauer PL. Surface electromyographic analysis of the low back muscles during rehabilitation exercises. J Orthop Sports Phys Ther 2008;38:736-745.

Freeman MD, Woodham MA, Woodham AW. The role of the lumbar multifidus in chronic low back pain: a review. PM R 2010;2:142-146.

Goubert D, Oosterwijck JV, Meeus M, Danneels L. Structural changes of lumbar muscles in non-specific low back pain: a systematic review. Pain Physician 2016;19:E985-1000.

Hides JA, Jull GA, Richardson CA. Long-term effects of specific stabilizing exercises for first-episode low back pain. Spine (Phila Pa 1976) 2001; 26:E243-248. 
Hides JA, Richardson CA, Jull GA. Multifidus muscle recovery is not automatic after resolution of acute, first-episode low back pain. Spine (Phila Pa 1976) 1996;21:2763-2769.

Kahlaee AH, Ghamkhar L, Arab AM. Effect of the abdominal hollowing and bracing maneuvers on activity pattern of the lumbopelvic muscles during prone hip extension in subjects with or without chronic low back pain: a preliminary study. J Manipulative Physiol Ther 2017; 40:106-117.

Kiesel KB, Uhl TL, Underwood FB, Rodd DW, Nitz AJ. Measurement of lumbar multifidus muscle contraction with rehabilitative ultrasound imaging. Man Ther 2007;12:161-166.

Kim CR, Park DK, Lee ST, Ryu JS. Electromyographic changes in trunk muscles during graded lumbar stabilization exercises. PM R 2016;8: 979-989.

Kim T, Woo Y, Kim Y. Effect of abdominal drawing-in maneuver during hip extension on the muscle onset time of gluteus maximus, hamstring, and lumbar erector spinae in subjects with hyperlordotic lumbar angle. J Physiol Anthropol 2014;33:34.

Larivière C, Gagnon DH, Henry SM, Preuss R, Dumas JP. The effects of an 8-week stabilization exercise program on lumbar multifidus muscle thickness and activation as measured with ultrasound imaging in patients with low back pain: an exploratory study. PM R 2018;10:483493.

MacDonald D, Moseley GL, Hodges PW. Why do some patients keep hurting their back? Evidence of ongoing back muscle dysfunction during remission from recurrent back pain. Pain 2009;142:183-188.

Oliver GD, Stone AJ, Plummer H. Electromyographic examination of selected muscle activation during isometric core exercises. Clin J Sport Med 2010;20:452-457.

Park KN, Cynn HS, Kwon OY, Lee WH, Ha SM, Kim SJ, Weon JH. Effects of the abdominal drawing-in maneuver on muscle activity, pelvic motions, and knee flexion during active prone knee flexion in patients with lumbar extension rotation syndrome. Arch Phys Med Rehabil 2011;92:1477-1483.

van Dieën JH, Selen LP, Cholewicki J. Trunk muscle activation in low-back pain patients, an analysis of the literature. J Electromyogr Kinesiol 2003; 13:333-351.

Wallwork TL, Stanton WR, Freke M, Hides JA. The effect of chronic low back pain on size and contraction of the lumbar multifidus muscle. Man Ther 2009;14:496-500.

Wilke HJ, Wolf S, Claes LE, Arand M, Wiesend A. Stability increase of the lumbar spine with different muscle groups. A biomechanical in vitro study. Spine (Phila Pa 1976) 1995;20:192-198.

Wong AY, Parent EC, Funabashi M, Stanton TR, Kawchuk GN. Do various baseline characteristics of transversus abdominis and lumbar multifidus predict clinical outcomes in nonspecific low back pain? A systematic review. Pain 2013;154:2589-2602. 